\title{
Stages of Adoption for Fecal Occult Blood Test and Colonoscopy Tests for Colorectal Cancer Screening in Korea
}

Nhung Cam Bui, MD, MPH
Ha Na Cho, MPH${ }^{1}$
Yoon Young Lee, MPH²
Mina Suh, MD, PhD²
Boyoung Park, MD, PhD²
Jae Kwan Jun, MD, PhD',2
Yeol Kim, MD, PhD²
Kui Son Choi, PhD',2

${ }^{1}$ Graduate School of Cancer Science and Policy, National Cancer Center, Goyang, ${ }^{2}$ National Cancer Control Institute, National Cancer Center, Goyang, Korea

Correspondence: Kui Son Choi, $\mathrm{PhD}$ Graduate School of Cancer Science and Policy, National Cancer Center, 323 Ilsan-ro, Ilsandong-gu, Goyang 10408, Korea Tel: 82-31-920-2912

Fax: 82-31-920-2189

E-mail: kschoi@ncc.re.kr

Received February 13, 2017

Accepted May 6, 2017

Published Online May 10, 2017

\begin{abstract}
Purpose
While colorectal cancer (CRC) is common in Asian countries, screening for CRC is not. Moreover, CRC screening behaviors in Asian populations remain largely unknown. The present study aimed to investigate the stages of adopting CRC screening in Korea according to screening modality.
\end{abstract}

\section{Materials and Methods}

Data were obtained from the 2014 Korean National Cancer Screening Survey, a cross-sectional survey that utilized nationally representative random sampling to investigate cancer screening rates. A total of 2,066 participants aged 50-74 years were included in this study. Chi-square test and multinomial logistic regression were applied to determine stages of adoption for fecal occult blood test (FOBT) and colonoscopy and factors associated with each stage.

\section{Results}

Of 1,593 participants included in an analysis of stage of adoption for FOBT, $36 \%$ were in action/maintenance stages, while $18 \%, 40 \%$, and $6 \%$ were in precontemplation, contemplation, and relapse/relapse risk stages, respectively. Of 1,371 subjects included in an analysis of stage of adoption for colonoscopy, $48 \%$ were in action/maintenance stages, with $21 \%$ in precontemplation, $21 \%$ in contemplation, and $11 \%$ in relapse/relapse risk stages. Multinomial logistic regression highlighted sex, household income, place of residency, family history of cancer, having private cancer insurance, smoking status, alcohol use, and regular exercise as being associated with stages of adoption for FOBT and colonoscopy.

\section{Conclusion}

This study outlines the distributions of stages of adoption for CRC screening by screening modality. Interventions to improve screening rates should be tailored to individuals in particular stages of adoption for CRC screening by modality.

\section{Introduction}

Colorectal cancer $(\mathrm{CRC})$ is a common malignancy and the leading cause of cancer-related deaths worldwide [1]. CRC is the third most frequent cancer in men $(746,000$ cases, $10.0 \%$ of all cancers) and the second in women $(614,000$ cases, $9.2 \%$ of all cancers) worldwide. While nearly $55 \%$ of all CRC cases

\section{Key words}

Colorectal neoplasms, Mass screening, Health behavior, Korea, Occult blood, Colonoscopy occur in more developed regions, the overall mortality rate thereof is relatively low $(694,000$ deaths, $8.5 \%$ of all CRC cases): most deaths (52\%) from CRC tend to occur in less developed regions of the world [1]. As with other cancers, access to screening programs and to appropriate treatment likely accounts for these variations in CRC survival between countries.

With evidence suggesting that screening reduces CRC 
mortality and incidence [2-5], CRC screening via fecal occult blood test (FOBT) or colonoscopy has been widely recommended [6]. Going further, several countries have adopted the use of FOBT in population-based CRC screening programs $[7,8]$. Interestingly, although colonoscopy is widely used as a gold standard to detect adenomas and CRC through visual inspection [9], uptake of screening colonoscopy has been shown to generally be poor [5]. In Korea, both tests are available through either opportunistic or organized screening programs. The National Cancer Screening Program (NCSP) for CRC, which was implemented in 2004 [10], offers annual testing with a single fecal immunochemical test (FIT) to men and women over 50 years of age and follow-up examinations with either colonoscopy (with biopsy if indicated) or double contrast barium enema for subjects with a positive FIT result.

Despite evidence that screening can reduce the incidence of and mortality from CRC, globally, only half the eligible population undergoes CRC screening [11-13]. For most Asian countries in particular, CRC screening is not commonly practiced, and CRC screening behaviors remain largely unknown. Recently, although a few studies have been conducted to examine factors associated with CRC screening in Korea [14-17], none have sought to examine factors related to stages of readiness for CRC screening by individual screening modalities. Moreover, most studies have only focused on whether a subject has or has not undergone CRC screening. According to the transtheoretical model (TTM), however, the acquisition and maintenance of health-protective behaviors are not all-or-nothing phenomena [18]: the TTM categorizes screening adoption into several stages of screening adoption, based on past and recent screening behaviors and future intentions to undergo screening [18].
In this study, we applied the TTM to examine the distribution of and factors associated with stages of adoption for FOBT and colonoscopy for CRC screening in Korea.

\section{Materials and Methods}

\section{Study population}

Data were obtained from the Korean National Cancer Screening Survey (KNCSS), which is an annual cross-sectional survey designed to investigate screening rates among Koreans for five common cancers (gastric, liver, colorectal, breast, and cervix) through nationally representative random sampling [19]. The 2014 KNCSS included men of ages from 40 to 74 years and women of ages from 30 to 74 years, who were selected based on Resident of Registration Population data collected by Statistics Korea, using multistage random sampling according to sex, age, geographic area, and size of population per area. The 2014 KNCSS included 4,000 participants, among a total of 28,571 random samples (total response rate: $14.0 \%$ ). The response rate after making contact was $40 \%$, excluding those who were absent $(17,173)$ or who did not meet the criteria for the survey $(1,629)$. Of the 4,000 participants, 2,122 men and women of ages ranging from 50 to 74 years old were asked about their experiences with CRC screening, since the NCSP provides CRC screening for individuals aged 50 years and older. Participants were asked whether they had undergone an FOBT, colonoscopy, or double-contrast barium enema for CRC screening (picture cards were shown to describe the test methods). Then, those who

Table 1. Stages of adoption for colorectal cancer screening by screening modality

\begin{tabular}{|c|c|c|}
\hline & FOBT & Colonoscopy \\
\hline Pre-contemplation & $\begin{array}{l}\text { No history of CRC screening and } \\
\text { no intention to do so }\end{array}$ & $\begin{array}{l}\text { No history of CRC screening and } \\
\text { no intention to do so }\end{array}$ \\
\hline \multirow[t]{2}{*}{ Contemplation } & $\begin{array}{l}\text { No history of CRC but planned } \\
\text { to get CRC screening }\end{array}$ & $\begin{array}{l}\text { No history of CRC but planned to get } \\
\text { CRC screening }\end{array}$ \\
\hline & $\begin{array}{l}\text { Has had FOBT more than } 1 \text { year prior } \\
\text { and has intentions to have an FOBT }\end{array}$ & $\begin{array}{l}\text { Has had colonoscopy more than } 10 \text { years prior and } \\
\text { has intentions to have a colonoscopy }\end{array}$ \\
\hline Action/Maintenance & $\begin{array}{l}\text { Has had first FOBT within the past } 1 \text { year and } \\
\text { is planning to have another one }\end{array}$ & $\begin{array}{l}\text { Has had first colonoscopy within the past } 10 \text { years } \\
\text { and is planning to have another one }\end{array}$ \\
\hline Relapse risk & $\begin{array}{l}\text { Has had first FOBT within the past } 1 \text { year } \\
\text { but no plans to get another FOBT }\end{array}$ & $\begin{array}{l}\text { Has had first colonoscopy within the past } 10 \text { years } \\
\text { but no plans to get another colonoscopy }\end{array}$ \\
\hline Relapse & $\begin{array}{l}\text { Has previously had an FOBT more than } \\
1 \text { year prior, but no plans to get another FOBT }\end{array}$ & $\begin{array}{l}\text { Has previously had a colonoscopy more than } \\
10 \text { years prior, but no plans to get another colonoscopy }\end{array}$ \\
\hline
\end{tabular}

FOBT, fecal occult blood test; CRC, colorectal cancer. 
had at least one CRC screening were asked about the most recent time they underwent the test and their plans to undergo future testing. In this study, 56 participants who underwent a double-contrast barium enema test only were excluded due to the small number thereof. Thus, a total of 2,066 participants aged 50 to 74 years old were finally included in the analysis.

Written informed consent was obtained from all study participants before being interviewed face-to-face in the KNCSS. This study was approved by the Institutional Review Board (IRB) of the National Cancer Center, Korea (No. NCCNCS08-129).

\section{Measurement}

The stages of adoption for CRC screening were evaluated using a modified, five-stage process developed to assess a subject's reported history of screening and their current intentions to undergo screening, as recommended by Rakowski et al. in 1996 [20]. Individuals who had undergone either an FOBT or colonoscopy were interviewed about their most recent test and their plans to undergo another test in the future. According to these questions, the participants were classified as follows for each screening modality (Table 1): individuals who had never undergone CRC screening and did not plan to undergo screening were classified into the pre-contemplation stage. Those who had either never undergone CRC screening or had not within recommended time intervals for screening, but were planning to do so within the next interval, were classified into the contemplation stage. The recommended time intervals are 1 year for FOBT and 10 years for colonoscopy [21]. The action/maintenance stages comprised subjects who complied with CRC screening recommendations: those who had undergone FOBT screening within the last 12 months and were planning to undergo another test within the next 12 months or those who had undergone colonoscopy screening within the last 10 years and were planning to undergo another test within the next 10 years. The relapse risk stage included subjects who had undergone CRC screening (either FOBT or colonoscopy) within the recommended time intervals, but were not planning to undergo another test within the time intervals. Individuals who had undergone FOBT more than 12 months before or colonoscopy more than 10 years before, but had no plans to undergo CRC screening, were classified into the relapse stage.

We also examined other socioeconomic variables (age, marital status, level of education, monthly household income, and residence area), family history of cancer, individual preferences for FOBT and colonoscopy as a CRC screening modality, health status, worry about getting cancer, and health related behaviors variables (smoking status, alcohol use, regular exercise, and regular visits to a doctor). Furthermore, enrollment in private cancer insurance was also measured to assess accessibility to CRC screening: although the National Health Insurance Service (NHIS) provides universal coverage to all Koreans, many Koreans pay for supplementary private health insurance in the event of illness (e.g., cancer or stroke) due to insufficient coverage by the NHIS.

\section{Statistical analysis}

Descriptive statistics were used to analyze the participants' characteristics and the distribution of stages of adoption. Frequencies with percentages were calculated for categorical variables. Chi-square test was used to compare the distribution of stages of adoption according to sociodemographic characteristics.

To determine factors related to one's stage of adoption, we grouped participants into four groups: (1) pre-contemplation, (2) contemplation, (3) action/maintenance, and (4) relapse risk/relapse groups. Due to the small numbers of subjects in the relapse and relapse risk stages, we combined both stages into one category in the analysis. Furthermore, people in the relapse risk and relapse stages share the same experience in that they have already experienced the action or maintenance stage. Simple tables were produced to verify the consistency of the data. Then, univariate multinomial logistic analysis was conducted to identify factors associated with each adoption stage according to screening modality. All variables with a $p$-value of $<0.1$ in univariate analysis were included in the multinomial logistic regression model as potential predictors. Likelihood ratio test was applied to compare significant differences for an added variable to the model. We assessed the adjusted odds of being in the precontemplation, contemplation, or relapse risk/relapse group rather than the action/maintenance group. All statistical analyses were performed using STATA software, ver. 12 (Stata Corp. L.P., College Station, TX), and all p-values of $<0.05$ were considered statistically significant.

\section{Results}

The sociodemographic characteristics of the participants are described in Table 2. The mean age of the study population was 58.9 years, and $50.8 \%$ were female. More than $80 \%$ had completed high school or higher; $91 \%$ of the participants lived with their spouse; $45 \%$ lived in a metropolitan area; and more than half of study population reported good health status. More than $80 \%$ of the participants had private cancer insur- 
Table 2. Sociodemographic characteristics of the Korean participants in 2014

\begin{tabular}{|c|c|c|c|c|}
\hline Characteristic & Total $(n=2,066)$ & FOBT $^{\mathrm{a})}(\mathrm{n}=1,077)$ & Colonoscopy $^{\mathrm{b}}(\mathrm{n}=855)$ & Neverc) $(n=516)$ \\
\hline \multicolumn{5}{|l|}{ Sex } \\
\hline Men & $1,017(49.2)$ & $543(50.4)$ & $451(52.8)$ & $238(46.1)$ \\
\hline Women & $1,049(50.8)$ & $534(49.6)$ & $404(47.3)$ & $278(53.9)$ \\
\hline \multicolumn{5}{|l|}{ Age (yr) } \\
\hline $50-59$ & $1,187(57.5)$ & $600(55.7)$ & $470(55.0)$ & $304(58.9)$ \\
\hline $60-69$ & $660(31.9)$ & $354(32.9)$ & $301(35.2)$ & $156(30.2)$ \\
\hline 70-74 & $219(10.6)$ & $123(11.4)$ & $84(9.8)$ & $56(10.9)$ \\
\hline \multicolumn{5}{|c|}{ Monthly household income } \\
\hline Less than $\$ 2,999$ & $573(27.7)$ & $310(28.8)$ & $243(28.4)$ & $137(26.6)$ \\
\hline$\$ 3,000-3,999$ & $453(21.9)$ & $224(20.8)$ & $183(21.4)$ & $118(22.9)$ \\
\hline$\$ 4,000-4,999$ & $524(25.4)$ & $280(26.0)$ & $202(23.6)$ & $133(25.8)$ \\
\hline More than $\$ 5,000$ & $516(25.0)$ & $263(24.4)$ & $227(26.6)$ & $128(24.8)$ \\
\hline \multicolumn{5}{|l|}{ Education } \\
\hline Less than high school & $411(19.9)$ & $215(20.0)$ & $158(18.5)$ & $115(22.3)$ \\
\hline High school or college & $1,173(56.8)$ & $614(57.0)$ & $484(56.6)$ & $289(56.0)$ \\
\hline More than college & $482(23.3)$ & $248(23.0)$ & $213(24.9)$ & $112(21.7)$ \\
\hline \multicolumn{5}{|l|}{ Marital status } \\
\hline Without a spouse & $192(9.3)$ & $94(8.7)$ & $75(8.8)$ & $55(10.7)$ \\
\hline With a spouse & $1,874(90.7)$ & $983(91.3)$ & $780(91.2)$ & $89.3(89.3)$ \\
\hline \multicolumn{5}{|l|}{ Residency } \\
\hline Metropolitan & $938(45.4)$ & $508(47.2)$ & $398(46.6)$ & $200(38.8)$ \\
\hline Non-metropolitan & $1,128(54.6)$ & $569(52.8)$ & $457(53.5)$ & $316(61.2)$ \\
\hline \multicolumn{5}{|l|}{ Private insurance } \\
\hline Yes & $1,721(83.3)$ & $899(83.5)$ & $710(83.0)$ & $421(81.6)$ \\
\hline No & $345(16.7)$ & $178(16.5)$ & $145(17.0)$ & $95(18.4)$ \\
\hline \multicolumn{5}{|l|}{ Family history of cancer } \\
\hline Yes & $364(17.6)$ & $169(15.7)$ & $163(19.1)$ & $97(18.8)$ \\
\hline No & $1,702(82.4)$ & $908(84.3)$ & $692(80.9)$ & $419(81.2)$ \\
\hline \multicolumn{5}{|l|}{ FOBT preference } \\
\hline Very much & $575(27.8)$ & $343(31.9)$ & $212(24.8)$ & $139(26.9)$ \\
\hline Somewhat & $1,021(49.4)$ & $541(50.2)$ & $417(48.8)$ & $260(50.4)$ \\
\hline Little & $375(18.2)$ & $154(14.3)$ & $181(21.2)$ & $94(18.2)$ \\
\hline Never & $90(4.4)$ & $37(3.4)$ & $43(5.0)$ & $20(3.9)$ \\
\hline Do not know & $5(0.2)$ & $2(0.2)$ & $2(0.2)$ & $3(0.6)$ \\
\hline \multicolumn{5}{|l|}{ Colonoscopy preference } \\
\hline Very much & $420(20.3)$ & $227(21.1)$ & $187(21.9)$ & $100(19.4)$ \\
\hline Somewhat & $1,288(62.3)$ & $658(61.1)$ & $554(64.8)$ & $312(60.5)$ \\
\hline Little & $331(16.0)$ & $178(16.5)$ & $106(12.4)$ & $95(18.4)$ \\
\hline Never & $15(0.7)$ & $7(0.7)$ & $3(0.4)$ & $5(1.0)$ \\
\hline Do not know & $12(0.6)$ & $7(0.7)$ & $5(0.6)$ & $4(0.8)$ \\
\hline \multicolumn{5}{|l|}{ Colorectal polyps } \\
\hline Yes & $45(2.2)$ & $30(2.8)$ & $30(3.5)$ & $6(1.2)$ \\
\hline No & $2,021(97.8)$ & $1,047(97.2)$ & 825 (96.5) & $510(98.8)$ \\
\hline \multicolumn{5}{|l|}{ Health status } \\
\hline Good & $1,102(53.3)$ & $567(52.7)$ & $435(50.9)$ & $275(53.3)$ \\
\hline Normal & $844(40.9)$ & $452(42.0)$ & 378 (44.2) & $202(39.2)$ \\
\hline Poor & $120(5.8)$ & $58(5.4)$ & $42(4.9)$ & $39(7.6)$ \\
\hline \multicolumn{5}{|l|}{ Cancer worry } \\
\hline Often & $553(26.8)$ & $292(27.1)$ & $241(28.2)$ & $130(25.2)$ \\
\hline Sometimes & $1,110(53.7)$ & $570(52.9)$ & $452(52.9)$ & $280(54.3)$ \\
\hline Rarely/Not at all & $403(19.5)$ & $215(20.0)$ & $162(189)$ & $106(20.5)$ \\
\hline
\end{tabular}

(Continued to the next page) 
Table 2. Continued

\begin{tabular}{|c|c|c|c|c|}
\hline Characteristic & Total $(n=2,066)$ & FOBT $^{\text {a) }}(n=1,077)$ & Colonoscopy $^{\mathrm{b})}(\mathrm{n}=855)$ & Never $^{c)}(n=516)$ \\
\hline \multicolumn{5}{|c|}{ Have a regular doctor } \\
\hline Yes & $1,005(48.6)$ & $546(50.7)$ & $432(50.5)$ & $238(46.1)$ \\
\hline No & $1,061(51.4)$ & $531(49.3)$ & $423(49.5)$ & $278(53.9)$ \\
\hline \multicolumn{5}{|l|}{ Smoking status } \\
\hline Non-smokers & $1,182(57.2)$ & $613(56.9)$ & $465(55.4)$ & $302(58.5)$ \\
\hline Past-smokers & $329(15.9)$ & 189 (17.6) & $155(18.1)$ & $66(12.8)$ \\
\hline Current smokers & $555(26.9)$ & $275(25.5)$ & $235(27.5)$ & $148(28.7)$ \\
\hline \multicolumn{5}{|l|}{ Alcohol use } \\
\hline Never & $723(35.0)$ & $364(33.8)$ & $296(34.6)$ & 185 (35.9) \\
\hline$\leq$ Once a month & $405(19.6)$ & $216(20.1)$ & $169(19.8)$ & $93(18.0)$ \\
\hline > Once a month & $938(45.4)$ & $497(46.1)$ & $390(45.6)$ & $238(46.1)$ \\
\hline \multicolumn{5}{|l|}{ Regular exercise } \\
\hline Yes & $1,087(52.6)$ & $578(53.7)$ & $457(53.5)$ & $243(47.1)$ \\
\hline No & $979(47.4)$ & 499 (46.3) & $398(46.6)$ & $273(52.9)$ \\
\hline
\end{tabular}

Values are presented as number (\%). FOBT, fecal occult blood test. ${ }^{\mathrm{a})}$ Participants who had FOBT at least one time, ${ }^{\text {b) Participants }}$ who had colonoscopy at least one time, ${ }^{\mathrm{c}}$ Participants who have never had either FOBT or colonoscopy.

ance, and $17.6 \%$ had a family history of cancer. Of the 2,066 participants, 1,077 (52.1\%) had undergone FOBT and 855 $(41.4 \%)$ had undergone only colonoscopy at least one time during their lifetime. Only 518 participants $(25.1 \%)$ had never undergone either FOBT or colonoscopy in their lifetime. Among those who had ever undergone FOBT, 382 participants had also undergone colonoscopy, accounting for $18.5 \%$ of the entire study population.

Table 3 shows the stages of adoption for FOBT and colonoscopy according to population characteristics. In this analysis, we combined the relapse risk and the relapse stages. Among 1,593 participants who were included in the analysis of stages of adoption for FOBT, 17.7\% were classified in the pre-contemplation stage, $40.2 \%$ in the contemplation stage, $36 \%$ in the action/maintenance stages, and $6.1 \%$ in the relapse risk/relapse stages. Among 1,371 participants who were included in the analysis of stages of adoption for colonoscopy, $20.6 \%, 20.8 \%, 48.1$, and $36 \%$ were categorized into the precontemplation, contemplation, action/maintenance, and relapse risk/relapse stages, respectively. Sex, monthly household income, residential area, family history of cancer, preferences for a screening modality, having private cancer insurance, smoking status, and regular exercise differed significantly across the stages of adoption for FOBT. Meanwhile, only sex, residency, a preference for colonoscopy, and health status differed with statistical significance across the stages of adoption for colonoscopy.

Tables 4 and 5 show the results of our multivariate multinomial logistic regression of factors associated with each stage of adoption for FOBT and colonoscopy. Compared with sub- jects who were in the action/maintenance stages for FOBT, women and subjects with a family history of CRC, living in a rural area, and current smokers were more likely to be in the precontemplation stage. Meanwhile, subjects who were 60-69 years old, female, had higher education and income level, had private health insurance, and were past or current smokers were less likely to be in the contemplation stage. However, those who had a family history of CRC were more likely to be in the contemplation stage. Between the action/maintenance and relapse/relapse risk stages, those living in a metropolitan area and past-smokers were less likely to be in the relapse/ relapse risk stages.

Regarding factors related to CRC screening via colonoscopy test, women and current smokers were more likely to be in the precontemplation stage than in the action/maintenance stages. However, individuals living in a metropolitan area and who preferred to undergo colonoscopy were less likely to be in the precontemplation stage than in the action/maintenance stages. Meanwhile, subjects who were 60-69 years old, had higher education level, had a family history of cancer, and exercised regularly were less likely to be in the contemplation stage. However, those who drank more than once a month and who were in poor health status were more likely to be in the contemplation stage than in the action/maintenance stages. Further, those who were of poor health status were more likely to be in the relapse/relapse risk stages than the action/maintenance stages. 


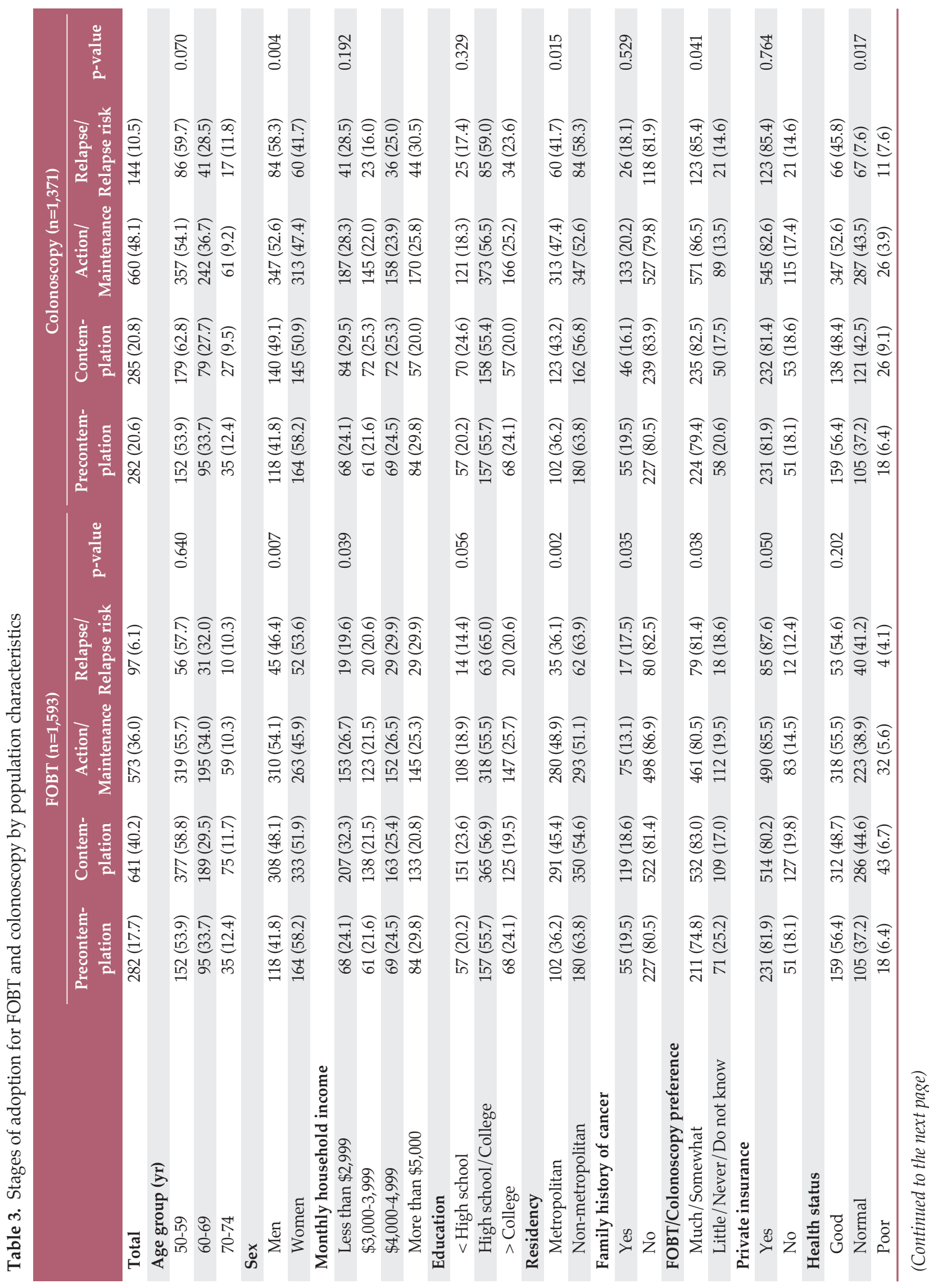




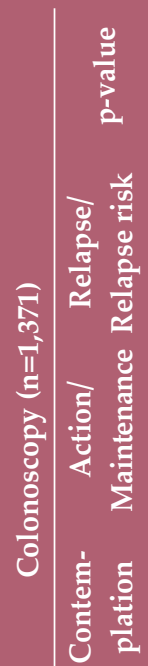

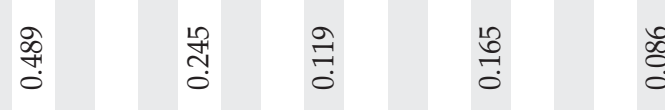

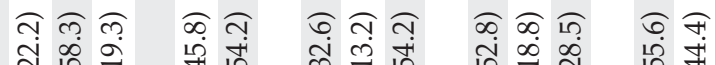

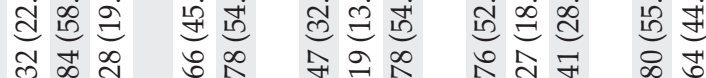

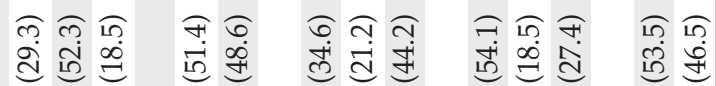

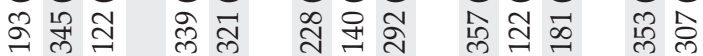

๙ิดิ

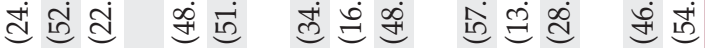

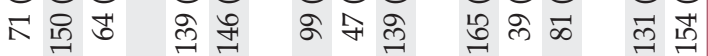

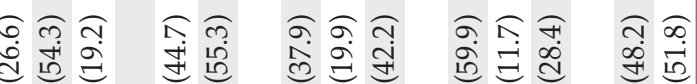

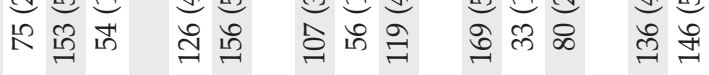

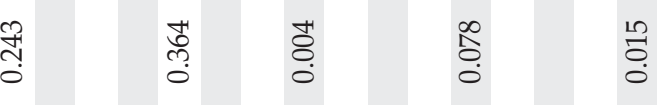

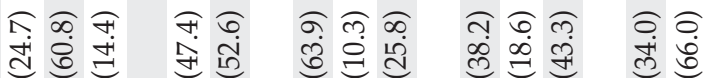

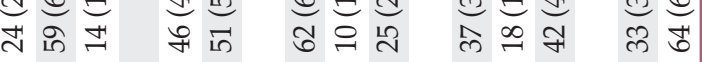

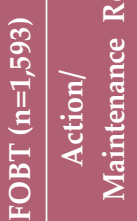

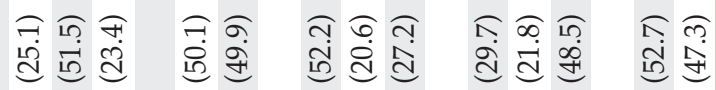

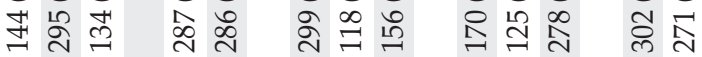

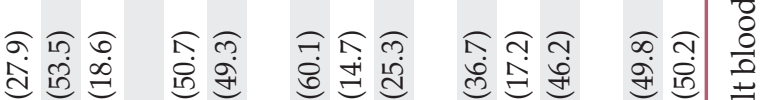

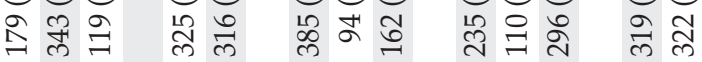

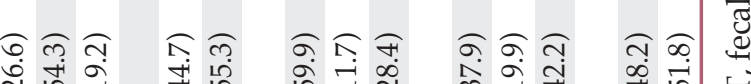

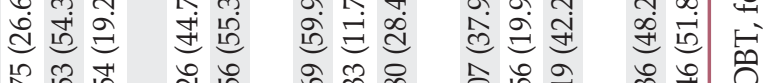

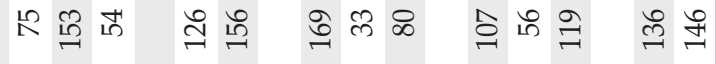

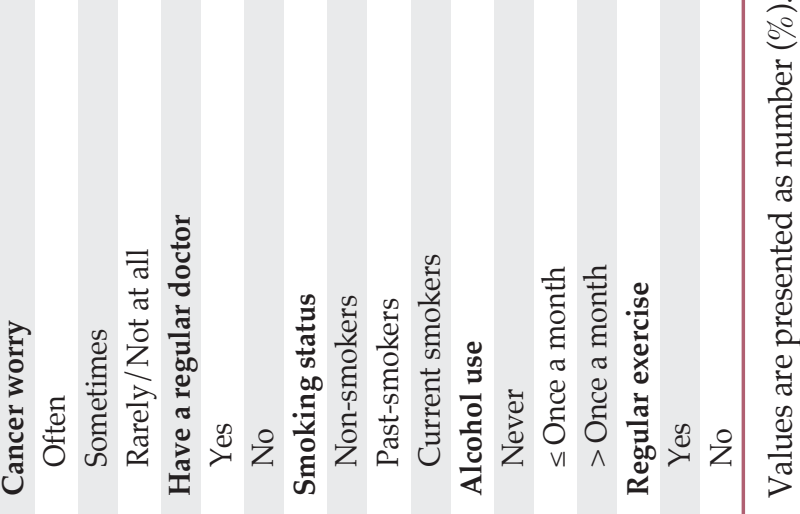


Table 4. Multivariate multinomial logistic regression for factors associated with stages of adoption for FOBT ${ }^{a}(n=1,593)$

\begin{tabular}{|c|c|c|c|c|c|c|}
\hline & \multicolumn{2}{|c|}{ Precontemplation $^{\text {b) }}$} & \multicolumn{2}{|c|}{ Contemplation $^{\text {b) }}$} & \multicolumn{2}{|c|}{ Relapse/Relapse risk ${ }^{\text {b) }}$} \\
\hline & aOR & $95 \% \mathrm{CI}$ & aOR & $95 \% \mathrm{CI}$ & aOR & $95 \% \mathrm{CI}$ \\
\hline \multicolumn{7}{|l|}{ Age (yr) } \\
\hline $50-59$ & 1.00 & & 1.00 & & 1.00 & \\
\hline $60-69$ & 1.03 & $0.74-1.44$ & 0.69 & $0.53-0.91$ & 0.99 & $0.61-1.63$ \\
\hline $70-74$ & 1.16 & $0.72-1.90$ & 0.83 & $0.56-1.24$ & 1.18 & $0.55-2.53$ \\
\hline \multicolumn{7}{|l|}{ Sex } \\
\hline Men & 1.00 & & 1.00 & & 1.00 & \\
\hline Women & 3.28 & $1.52-7.05$ & 0.84 & $0.52-1.33$ & 0.79 & $0.35-1.78$ \\
\hline \multicolumn{7}{|l|}{ Education } \\
\hline Less than high school & 1.00 & & 1.00 & & 1.00 & \\
\hline High school or college & 0.90 & $0.60-1.35$ & 0.88 & $0.64-1.20$ & 1.24 & $0.64-2.38$ \\
\hline More than college & 0.82 & $0.52-1.31$ & 0.63 & $0.44-0.92$ & 0.83 & $0.39-1.78$ \\
\hline \multicolumn{7}{|l|}{ Monthly household income } \\
\hline Less than $\$ 2,999$ & 1.00 & & 1.00 & & 1.00 & \\
\hline$\$ 3,000-3,999$ & 1.18 & $0.76-1.83$ & 0.84 & $0.60-1.19$ & 1.15 & $0.58-2.32$ \\
\hline$\$ 4,000-4,999$ & 1.07 & $0.70-1.64$ & 0.80 & $0.58-1.11$ & 1.39 & $0.73-2.66$ \\
\hline More than $\$ 5,000$ & 1.38 & $0.91-2.10$ & 0.69 & $0.50-0.97$ & 1.47 & $0.76-2.82$ \\
\hline \multicolumn{7}{|l|}{ Residency } \\
\hline Non-metropolitan & 1.00 & & 1.00 & & 1.00 & \\
\hline Metropolitan & 0.57 & $0.42-0.78$ & 0.82 & $0.65-1.05$ & 0.60 & $0.38-0.96$ \\
\hline \multicolumn{7}{|l|}{ Family history of cancer } \\
\hline No & 1.00 & & 1.00 & & 1.00 & \\
\hline Yes & 1.73 & $1.16-2.57$ & 1.50 & $1.08-2.08$ & 1.49 & $0.82-2.70$ \\
\hline \multicolumn{7}{|l|}{ FOBT preference } \\
\hline Little/Never/Do not know & 1.00 & & 1.00 & & 1.00 & \\
\hline Much/Somewhat & 0.81 & $0.57-1.14$ & 1.26 & $0.94-1.70$ & 1.16 & $0.67-2.04$ \\
\hline \multicolumn{7}{|l|}{ Private insurance } \\
\hline No & 1.00 & & 1.00 & & 1.00 & \\
\hline Yes & 0.77 & $0.52-1.14$ & 0.72 & 0.53-0.99 & 1.14 & $0.59-2.22$ \\
\hline \multicolumn{7}{|l|}{ Health status } \\
\hline Good & 1.00 & & 1.00 & & 1.00 & \\
\hline Normal & 0.85 & $0.62-1.17$ & 1.27 & $0.99-1.62$ & 1.09 & $0.68-1.74$ \\
\hline Poor & 0.81 & $0.42-1.53$ & 1.17 & 0.70-1.95 & 0.77 & $0.25-2.34$ \\
\hline \multicolumn{7}{|l|}{ Smoking status } \\
\hline Non-smokers & 1.00 & & 1.00 & & 1.00 & \\
\hline Past-smokers & 1.30 & $0.57-2.96$ & 0.46 & $0.28-0.76$ & 0.35 & $0.13-0.92$ \\
\hline Current smokers & 2.63 & $1.19-5.82$ & 0.61 & $0.37-0.99$ & 0.70 & $0.30-1.65$ \\
\hline \multicolumn{7}{|l|}{ Alcohol use } \\
\hline Never & 1.00 & & 1.00 & & 1.00 & \\
\hline$\leq$ Once a month & 0.88 & $0.57-1.35$ & 0.72 & $0.51-1.02$ & 0.86 & $0.45-1.66$ \\
\hline$>$ Once a month & 0.99 & $0.62-1.59$ & 1.04 & $0.73-1.50$ & 0.91 & $0.46-1.82$ \\
\hline \multicolumn{7}{|l|}{ Regular exercise } \\
\hline Yes & 0.79 & $0.58-1.07$ & 0.80 & $0.63-1.02$ & 1.51 & $0.95-2.42$ \\
\hline No & 1.00 & & 1.00 & & 1.00 & \\
\hline
\end{tabular}

FOBT, fecal occult blood test; aOR, adjusted odds ratio; CI, confidence interval. ${ }^{\text {a) }}$ All variables in the table were included in

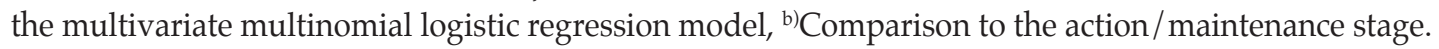


Table 5. Multivariate multinomial logistic regression for factors associated with stages of adoption for colonoscopy ${ }^{\text {a) }}$ $(\mathrm{n}=1,371)$

\begin{tabular}{|c|c|c|c|c|c|c|}
\hline & \multicolumn{2}{|c|}{ Precontemplation $^{\text {b) }}$} & \multicolumn{2}{|c|}{ Contemplation $^{\text {b) }}$} & \multicolumn{2}{|c|}{ Relapse/Relapse risk $^{\text {b) }}$} \\
\hline & aOR & $95 \% \mathrm{CI}$ & aOR & $95 \% \mathrm{CI}$ & $\mathrm{aOR}$ & $95 \% \mathrm{CI}$ \\
\hline \multicolumn{7}{|l|}{ Age (yr) } \\
\hline $50-59$ & 1.00 & & 1.00 & & 1.00 & \\
\hline $60-69$ & 0.91 & $0.66-1.25$ & 0.55 & $0.40-0.77$ & 0.67 & $0.44-1.03$ \\
\hline $70-74$ & 1.29 & $0.79-2.12$ & 0.69 & $0.40-1.17$ & 1.24 & $0.66-2.33$ \\
\hline \multicolumn{7}{|l|}{ Sex } \\
\hline Men & 1.00 & & 1.00 & & 1.00 & \\
\hline Women & 3.60 & $1.71-7.54$ & 1.25 & $0.71-2.20$ & 0.64 & $0.33-1.24$ \\
\hline \multicolumn{7}{|l|}{ Education } \\
\hline Less than high school & 1.00 & & 1.00 & & 1.00 & \\
\hline High school or college & 0.84 & $0.57-1.25$ & 0.70 & $0.48-1.03$ & 1.09 & $0.64-1.83$ \\
\hline More than college & 0.79 & $0.50-1.25$ & 0.56 & $0.36-0.88$ & 0.89 & $0.49-1.63$ \\
\hline \multicolumn{7}{|l|}{ Monthly household income } \\
\hline Less than $\$ 2,999$ & 1.00 & & 1.00 & & 1.00 & \\
\hline$\$ 3,000-3,999$ & 1.24 & $0.81-1.90$ & 1.12 & $0.74-1.68$ & 0.68 & $0.38-1.22$ \\
\hline$\$ 4,000-4,999$ & 1.28 & 0.84-1.95 & 0.99 & $0.66-1.49$ & 0.97 & $0.57-1.64$ \\
\hline More than $\$ 5,000$ & 1.41 & $0.93-2.12$ & 0.73 & $0.48-1.12$ & 1.11 & $0.67-1.84$ \\
\hline \multicolumn{7}{|l|}{ Residency } \\
\hline Non-metropolitan & 1.00 & & 1.00 & & 1.00 & \\
\hline Metropolitan & 0.60 & $0.44-0.82$ & 0.77 & $0.57-1.04$ & 0.80 & $0.55-1.17$ \\
\hline \multicolumn{7}{|l|}{ Family history of cancer } \\
\hline No & 1.00 & & 1.00 & & 1.00 & \\
\hline Yes & 0.97 & $0.68-1.41$ & 0.67 & $0.45-0.99$ & 0.75 & $0.46-1.22$ \\
\hline \multicolumn{7}{|l|}{ Colonoscopy preference } \\
\hline Little/Never/Do not know & 1.00 & & 1.00 & & 1.00 & \\
\hline Much/Somewhat & 0.67 & $0.46-0.98$ & 0.76 & $0.52-1.13$ & 0.92 & $0.55-1.56$ \\
\hline \multicolumn{7}{|l|}{ Private insurance } \\
\hline No & 1.00 & & 1.00 & & 1.00 & \\
\hline Yes & 0.99 & $0.67-1.45$ & 0.99 & $0.68-1.45$ & 1.31 & $0.78-2.22$ \\
\hline \multicolumn{7}{|l|}{ Health status } \\
\hline Good & 1.00 & & 1.00 & & 1.00 & \\
\hline Normal & 0.78 & $0.58-1.06$ & 1.12 & $0.83-1.52$ & 1.31 & $0.89-1.94$ \\
\hline Poor & 1.38 & $0.71-2.69$ & 2.94 & $1.59-5.43$ & 2.82 & $1.28-6.22$ \\
\hline \multicolumn{7}{|l|}{ Smoking status } \\
\hline Non-smokers & 1.00 & & 1.00 & & 1.00 & \\
\hline Past-smokers & 1.59 & $0.68-3.55$ & 0.62 & $0.33-1.16$ & 0.57 & $0.28-1.17$ \\
\hline Current smokers & 2.51 & $1.16-5.41$ & 0.74 & $0.41-1.34$ & 0.53 & $0.26-1.07$ \\
\hline \multicolumn{7}{|l|}{ Alcohol use } \\
\hline Never & 1.00 & & 1.00 & & 1.00 & \\
\hline$\leq$ Once a month & 1.03 & $0.68-1.56$ & 0.89 & $0.57-1.37$ & 0.72 & $0.39-1.31$ \\
\hline$>$ Once a month & 1.41 & $0.89-2.23$ & 1.83 & $1.17-2.87$ & 1.59 & $0.89-2.81$ \\
\hline \multicolumn{7}{|l|}{ Regular exercise } \\
\hline Yes & 0.78 & $0.58-1.05$ & 0.72 & $0.54-0.96$ & 1.02 & $0.70-1.49$ \\
\hline No & 1.00 & & 1.00 & & 1.00 & \\
\hline
\end{tabular}

aOR, adjusted odds ratio; $\mathrm{CI}$, confidence interval. a) All variables in the table were included in the multivariate multinomial

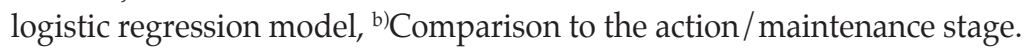




\section{Discussion}

This study identified the distribution of stages of adoption for FOBT and colonoscopy for CRC screening in Korea. Although FOBT is offered through the NCSP free of charge for Koreans over the age of 50 years, the percentage of respondents in the action/maintenance stages for FOBT $(36 \%)$ was still lower than that for colonoscopy $(48.1 \%)$. This indicates a preference among Koreans to receive CRC screening by colonoscopy over FOBT, even though they must do so at their own expense through opportunistic screening. Of the two tests, colonoscopy is the more accurate technique, although it is invasive, carries risks of bleeding and perforation, requires preparation and premedication, and involves much higher costs. While FOBT is a simple, safe, and inexpensive test with which to screen for CRC, its low sensitivity, mainly for premalignant lesions, necessitates recommendations for annual screening, with which many individuals may be reluctant to comply. For this reason potentially, the percentage of people who were in the action/maintenance stages for FOBT was low, while the percentage of people who were in the contemplation stage was relatively high (40\%). Meanwhile, however, although colonoscopy was more likely to be chosen in CRC screening among Koreans, FOBT screening rates have increased to greater extents than those for colonoscopy during the last decade: between 20042013, CRC screening rates for FOBT and colonoscopy increased from $3.8 \%$ to $27.6 \%$ (23.8\% increase) and $14.4 \%$ to $35.2 \%$ (20.8\% increase), respectively [19].

In the current study, we assessed five stages of readiness for FOBT and colonoscopy: precontemplation, contemplation, action/maintenance, relapse, and relapse risk. Only a few studies have examined the TTM model in relation to CRC screening behavior [22-27]. In multinomial logistic regression analysis of the stages of adoption, several factors were shown to influence differences in the distributions thereof. Primarily, females were more likely to be in precontemplation than in the action/maintenance stages for both FOBT and colonoscopy. Similar findings have also been reported in other studies $[24,27]$. One study suggested that CRC is perceived as a man's disease and that, therefore, women may be less concerned with CRC screening than they should be [28]. Furthermore, women older than 50 years are at risk for many sex-related diseases, such as breast, ovarian, and cervical cancers, and interestingly, this has been shown to lead to less attention being paid to CRC screening among women [27].

People with a higher education level and individuals living in a metropolitan area were more likely to be classified in onschedule stages (action/maintenance). Similar findings were observed in other studies $[17,24]$. These results imply that higher education and better accessibility to screening facilities are reinforcing factors for adherence to CRC screening. Remarkably, people who had a family history of cancer were less likely to be in the action/maintenance stages for FOBT adoption. On the other hand, people who had a family history of cancer were more likely to be in the action/maintenance stages for colonoscopy adoption. The higher adherence with colonoscopy testing among those with a family history of cancer might indicate a preference for colonoscopy testing among higher-risk individuals. This study also highlighted current smokers as being more likely to be in the precontemplation stage. This finding suggests that current smokers are less likely to be involved in preventive behaviors, such as screening.

Regarding colonoscopy test adoption, females were more likely to stay in the precontemplation stage than in the action/maintenance stages. Those who had a higher level of education, however, were more likely to be in action/maintenance stages. Additionally, subjects of ages from 60 to 69 years were more likely to be in the action/maintenance stages than the contemplation stage. Although previous studies have reported that individuals of higher income status are more likely to have undergone an up-to-date colonoscopy in Korea [11,17], we were unable to find a significant association between household income and stages of adoption for colonoscopy in the current study. In addition, subjects of poor health status were more likely to be in the contemplation and relapse/relapse risk stages than the action stage. We explain this observation as follows: colonoscopy is an invasive and uncomfortable procedure, and individuals with poor health status probably have additional health problems. Therefore, colonoscopy may not be a favorable test for them. Also, current smokers and those who drink more than once a month were more likely to be in precontemplation and contemplation stages than the action/ maintenance stages, while those who exercised regularly were more likely to be in the action stage. These suggest that people with an unhealthy lifestyle are less likely to be involved in CRC screening.

This study has several limitations. First, this study used cross-sectional survey data, which would limit interpretations of any causal relationships for the observed associations. Accordingly, future studies with a longitudinal design should be conducted to track patterns in CRC screening behaviors. Second, due to potential recall bias of selfreported screening history, we assessed only the most recent cancer screening event and did not collect information on screening events that preceded the most recent one. Thus, we could not distinguish between the action and maintenance stages as recommended by Rakowski et al. [20]. However, due to the long screening interval for colonoscopy (usually 10 years is recommended), it would not be feasible to cate- 
gorize the maintenance stage for colonoscopy. As another limitation in assessing stages of adoption, we could not identify subjects in the unaware stage (never heard of FOBT or colonoscopy) as in previous studies [27,29]. Finally, we were unable to explore the influences of other important correlates, such as test-specific characteristics (e.g., preparation, cost, time constraints, transportation, or geographic capacity for screening), process of change, self-efficacy, decisional balance, and psychological factors (e.g., discomfort, concern about complications, or anxiety about the procedure) involved in utilization of CRC screening and intentions to undergo future screening tests. Further studies are needed to delve into these factors and to provide a more comprehensive outline of the effects of these factors on stages of adoption for CRC screening in the TTM.

Despite all of the above limitations, this study is important in that it assessed CRC screening behaviors specifically in relation to two popular screening modalities among Koreans. The study results provide new insights that may be of use in guiding the development of intervention strategies for improving compliance with CRC screening recommendations at the population level. Our results demonstrated that rural, less educated, women were less likely to adhere with CRC screening. Moreover, those who had a family history of cancer showed better adherence with colonoscopy than with FOBT. Additionally, we showed that household income, private cancer insurance, and regularly exercise are positively associated with stages of FOBT adoption, while smokers and alcohol use are negatively associated with stages of FOBT and colonoscopy adoption. Accordingly, we suggest that interventions tailored to individuals in particular stages of adoption for CRC screening could help improve participation therein.

\section{Conflicts of Interest}

Conflict of interest relevant to this article was not reported.

\section{Acknowledgments}

The authors would like to thank the staff of the National Health Insurance Service. This study was supported by a Grant-in-Aid for Cancer Research and Control from the National Cancer Center of Korea (\#1310232).

\section{References}

1. Ferlay J, Soerjomataram I, Dikshit R, Eser S, Mathers C, Rebelo $\mathrm{M}$, et al. Cancer incidence and mortality worldwide: sources, methods and major patterns in GLOBOCAN 2012. Int J Cancer. 2015;136:E359-86.

2. Mandel JS, Bond JH, Church TR, Snover DC, Bradley GM, Schuman LM, et al. Reducing mortality from colorectal cancer by screening for fecal occult blood. Minnesota Colon Cancer Control Study. N Engl J Med. 1993;328:1365-71.

3. Mandel JS, Church TR, Bond JH, Ederer F, Geisser MS, Mongin SJ, et al. The effect of fecal occult-blood screening on the incidence of colorectal cancer. N Engl J Med. 2000;343:1603-7.

4. Quintero E, Castells A, Bujanda L, Cubiella J, Salas D, Lanas A, et al. Colonoscopy versus fecal immunochemical testing in colorectal-cancer screening. N Engl J Med. 2012;366:697-706.

5. Pox CP, Altenhofen L, Brenner H, Theilmeier A, Von Stillfried D, Schmiegel W. Efficacy of a nationwide screening colonoscopy program for colorectal cancer. Gastroenterology. 2012; 142:1460-7.e2.

6. US Preventive Services Task Force, Bibbins-Domingo K, Grossman DC, Curry SJ, Davidson KW, Epling JW Jr, et al. Screening for colorectal cancer: US Preventive Services Task Force recommendation statement. JAMA. 2016;315:2564-75.

7. Sung JJ, Ng SC, Chan FK, Chiu HM, Kim HS, Matsuda T, et al. An updated Asia Pacific Consensus Recommendations on colorectal cancer screening. Gut. 2015;64:121-32.

8. Schreuders EH, Ruco A, Rabeneck L, Schoen RE, Sung JJ,
Young GP, et al. Colorectal cancer screening: a global overview of existing programmes. Gut. 2015;64:1637-49.

9. European Colorectal Cancer Screening Guidelines Working Group, von Karsa L, Patnick J, Segnan N, Atkin W, Halloran $S$, et al. European guidelines for quality assurance in colorectal cancer screening and diagnosis: overview and introduction to the full supplement publication. Endoscopy. 2013;45:51-9.

10. Shim JI, Kim Y, Han MA, Lee HY, Choi KS, Jun JK, et al. Results of colorectal cancer screening of the National Cancer Screening Program in Korea, 2008. Cancer Res Treat. 2010;42: 191-8.

11. Choi KS, Jun JK, Lee HY, Hahm MI, Oh JH, Park EC. Increasing uptake of colorectal cancer screening in Korea: a population-based study. BMC Public Health. 2010;10:265.

12. Shapiro JA, Seeff LC, Thompson TD, Nadel MR, Klabunde CN, Vernon SW. Colorectal cancer test use from the 2005 National Health Interview Survey. Cancer Epidemiol Biomarkers Prev. 2008;17:1623-30.

13. Schenck AP, Peacock SC, Klabunde CN, Lapin P, Coan JF, Brown ML. Trends in colorectal cancer test use in the medicare population, 1998-2005. Am J Prev Med. 2009;37:1-7.

14. Han MA, Choi KS, Jun JK, Kim Y, Park EC, Lee HY. Factors associated with the intention to have colorectal cancer screening in Korean adults. Eur J Cancer Care (Engl). 2011;20:475-82.

15. Myong JP, Shin JY, Kim SJ. Factors associated with participation in colorectal cancer screening in Korea: the Fourth Korean 
National Health and Nutrition Examination Survey (KNHANES IV). Int J Colorectal Dis. 2012;27:1061-9.

16. Bae N, Park S, Lim S. Factors associated with adherence to fecal occult blood testing for colorectal cancer screening among adults in the Republic of Korea. Eur J Oncol Nurs. 2014;18:72-7.

17. Suh M, Choi KS, Lee HY, Hahm MI, Lee YY, Jun JK, et al. Socioeconomic disparities in colorectal cancer screening in Korea: a nationwide cross-sectional study. Medicine (Baltimore). 2015;94:e1368.

18. Kwak MS, Choi KS, Spring BJ, Park S, Park EC. Predicting the stages of adoption of cervical cancer screening among Korean women. Prev Med. 2009;49:48-53.

19. Suh M, Choi KS, Park B, Lee YY, Jun JK, Lee DH, et al. Trends in cancer screening rates among Korean men and women: results of the Korean National Cancer Screening Survey, 20042013. Cancer Res Treat. 2016;48:1-10.

20. Rakowski W, Ehrich B, Dube CE, Pearlman DN, Goldstein MG, Peterson KK, et al. Screening mammography and constructs from the transtheoretical model: Associations using two definitions of the stages-of-adoption. Ann Behav Med. 1996;18:91-100.

21. Lee BI, Hong SP, Kim SE, Kim SH, Kim HS, Hong SN, et al. Korean guidelines for colorectal cancer screening and polyp detection. Clin Endosc. 2012;45:25-43.

22. Costanza ME, Luckmann R, Stoddard AM, Avrunin JS, White
MJ, Stark JR, et al. Applying a stage model of behavior change to colon cancer screening. Prev Med. 2005;41:707-19.

23. Brenes GA, Paskett ED. Predictors of stage of adoption for colorectal cancer screening. Prev Med. 2000;31:410-6.

24. Wang HL, Christy SM, Skinner CS, Champion VL, Springston JK, Perkins SM, et al. Predictors of stage of adoption for colorectal cancer screening among African American primary care patients. Cancer Nurs. 2014;37:241-51.

25. Christie J, Jandorf L, Itzkowitz S, Halm E, Freeman K, King S, et al. Sociodemographic correlates of stage of adoption for colorectal cancer screening in African Americans. Ethn Dis. 2009;19:323-9.

26. Duncan A, Turnbull D, Gregory T, Cole SR, Young GP, Flight I, et al. Using the Transtheoretical Model of Behaviour Change to describe readiness to rescreen for colorectal cancer with faecal occult blood testing. Health Promot J Austr. 2012;23:122-8.

27. Trauth JM, Ling BS, Weissfeld JL, Schoen RE, Hayran M. Using the transtheoretical model to stage screening behavior for colorectal cancer. Health Educ Behav. 2003;30:322-36.

28. Burke W, Beeker C, Kraft JM, Pinsky L. Engaging women's interest in colorectal cancer screening: a public health strategy. J Womens Health Gend Based Med. 2000;9:363-71.

29. Ferrer RA, Hall KL, Portnoy DB, Ling BS, Han PK, Klein WM. Relationships among health perceptions vary depending on stage of readiness for colorectal cancer screening. Health Psychol. 2011;30:525-35. 